\title{
Improved System for Inspecting Minefields and Residual Explosives
}

\author{
D. Sudac, S. Majetić, K. Nađ, J. Obhođaš, and V. Valković
}

\begin{abstract}
A next generation system, as an upgrade of a robotic mobile system for anti-personnel landmine clearance, was considered. In contrast to the first generation system where the fast neutron activation method and the associated alpha particle imaging (API) was supposed to be used for finding the residual explosives and/or landmines, in the next generation system fast neutrons (FN) was considered to be used only for the confirmation of the explosive in the suspected object previously found by the ground penetrating radar (GPR), metal detector (MD) and infrared imaging (IR). Such system is expected to have the acceptable price and the optimal demining vehicle speed of $10 \mathrm{~cm} / \mathrm{s}$. In contrast to the previous system only one neutron generator (NG) is needed. In order to study the possibility of FN to confirm the presence of TNT explosive in the real environment the tests were made with the soil of different moisture contents. Comparative study was done by using the $7.62 \mathrm{~cm} \times 7.62 \mathrm{~cm} \mathrm{BGO}, 7.62 \mathrm{~cm} \times 7.62 \mathrm{~cm} \mathrm{LaBr}_{3}: \mathrm{Ce}$ and $7.62 \mathrm{~cm} \times 7.62 \mathrm{~cm} \mathrm{NaI}(\mathrm{Tl})$ gamma-ray detectors. Although nitrogen was easily detected in larger amount of TNT explosive, its signal was weak in detection of Anti-Personal (AP) mine like DLM2.4. The presences of soil additionally diminish the possibility of nitrogen detection even in the Anti-Tank mines (AT).
\end{abstract}

Index Terms-Antipersonnel landmine detection, associated particle imaging, fast neutrons, multisensor.

\section{INTRODUCTION}

M ECHANICAL demining, by using the special machines, provides significant savings over manual demining. Not only can more land be cleared, but human lives are saved as the process of manual demining is extremely dangerous. DOK-ING Ltd. developed the MV-4 and MV-10 mine clearance systems designed to clear various types of terrain containing Anti-Personnel (AP) mines, Anti-Tank (AT) mines and unexploded ordnance (UXO). AP and AT mines are destroyed by the force of impact of the attached flail tool. The flail tool is made of hardened steel shaft with hammers attached at the end of the chains. During mine clearance activities, the shaft rotates and the hammers strike the ground and shatter or activate embedded mines. The force of the flail hammers is optimized to enable cutting through dense vegetation and digging into soil. After the clearance of a minefield with such a system it is necessary to check

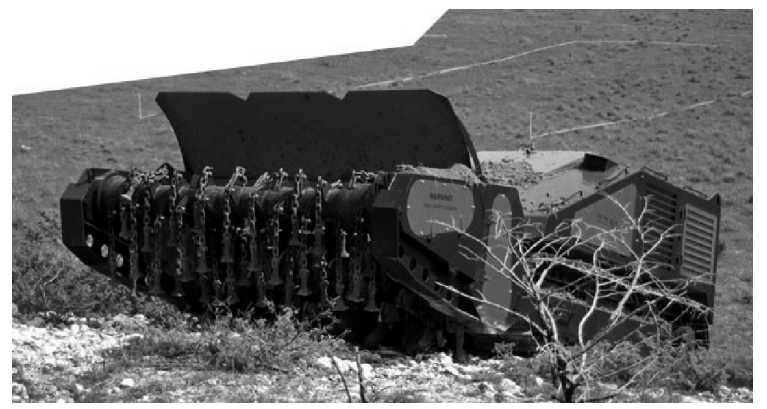

Fig. 1. MV-10 Double Tool Mine Clearance System (MV-10) is designed to clear various types of terrain containing Anti-Personnel (AP) mines, Anti-Tank (AT) mines, and unexploded ordnance (UXO).

the minefield for the presence of explosive residues of mass above $100 \mathrm{~g}$.

In the previous prototype [1] a neutron based system was proposed for the detection of TNT fragments and AP mines as an upgrade of robotic mobile systems such as MV-4 or MV-10. Proposed system contained twenty-one $7.62 \mathrm{~cm} \times 7.62 \mathrm{~cm} \mathrm{LaBr}_{3}$ : Ce gamma-ray detectors and six NG. Such a system had an operative radiation issue and high production cost as major drawbacks. In the next generation system a multi-sensor approach was considered instead of using neutron probe as the only sensor. To date, various prototype multisensor mine detector systems have been developed. As an example Canadian teleoperated landmine detection systems use five different technologies: electromagnetic induction, visible wavelength imaging, GPR for a quick scan of the minefield and thermal neutron analysis as a confirmation tool [2][3]. The combination of GPR and metal detector was discussed in [4][5]. The above technologies depend on various parameters like soil texture, bulk density and soil moisture [6]-[8]. GPR is especially sensitive to the soil water content. The API method for identification of TNT explosive in soil was analyzed also in [9][10]. In this paper we have shown that FN-API could be used as the explosive confirmation tool and soil moisture probe.

\section{Fast Neutrons and Associated Alpha Particle TECHNIQUE}

Fig. 2 shows the experimental setup. A neutron generator API 120 manufactured by ThermoElectron was used as a source of $14 \mathrm{MeV}$ neutron beam produced in ${ }^{3} \mathrm{H}(\mathrm{d}, \mathrm{n})^{4}$ He nuclear reaction. The alpha detector incorporated inside the NG was made from the YAP:Ce scintillator fixed to the NG and from the removable photomultiplier tube (PMT). The collimator in front of the PMT defined the opening angle of the tagged neutron cone which was $12^{\circ}$. 


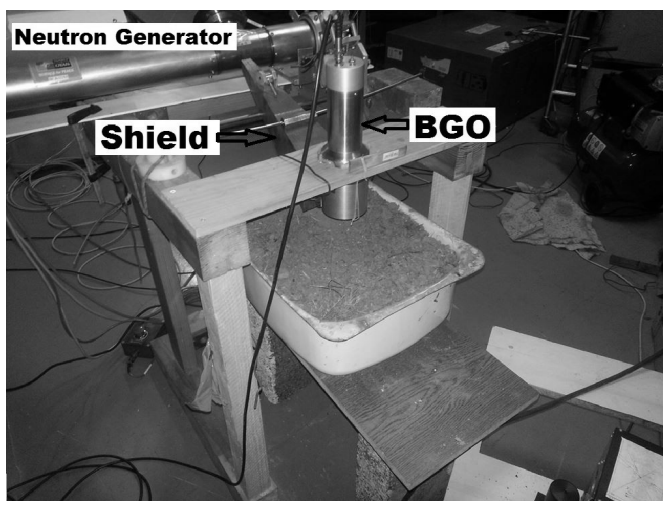

Fig. 2. Experimental set-up with NG, API 120, BGO gamma ray detector, iron shield and soil target.
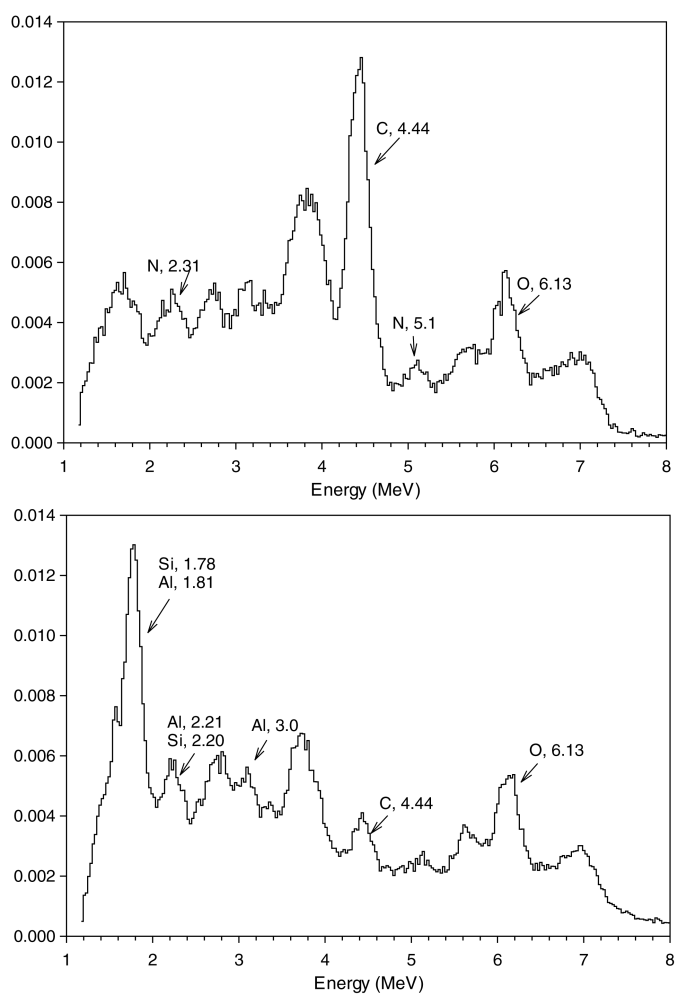

Fig. 3. Gamma-ray spectrum of TNT surrogate $\mathrm{C}_{7} \mathrm{~N}_{3} \mathrm{O}_{6} \mathrm{H}_{6}$ (upper) and the gamma-ray spectrum of dry soil (lower) recorded with the BGO detector.

The $7.62 \mathrm{~cm} \times 7.62 \mathrm{~cm} \mathrm{BGO}$ or $7.62 \mathrm{~cm} \times 7.62 \mathrm{~cm} \mathrm{LaBr}_{3}:$ Ce gamma-ray detector was used. Between the gamma-ray detector and the NG was a shield protecting the detector from the direct radiation of neutrons. A soil target was put below the gamma-ray detector few centimeters apart from the detector.

Fig. 3 shows the gamma-ray spectra of a TNT surrogate with mass of $0.90 \mathrm{~kg}$ in a plastic container and the gamma-ray spectrum of dry soil. Spectra were normalized in the way that the integral over the gamma-ray energies was equal to one. The TNT surrogate contained $0.158 \%$ wt of graphite, $0.276 \%$ wt of dihydrate oxalic acid and $0.566 \%$ wt of cyanuric acid. The density was $0.90 \mathrm{~g} / \mathrm{cm}^{3}$. Carbon-to-oxygen and carbon-to-nitrogen ratio resembled those in the real TNT explosive, but carbon-to-hydrogen ratio was $7 / 6$ instead of $7 / 5$. Carbon, oxygen and nitrogen peaks were clearly visible in the TNT

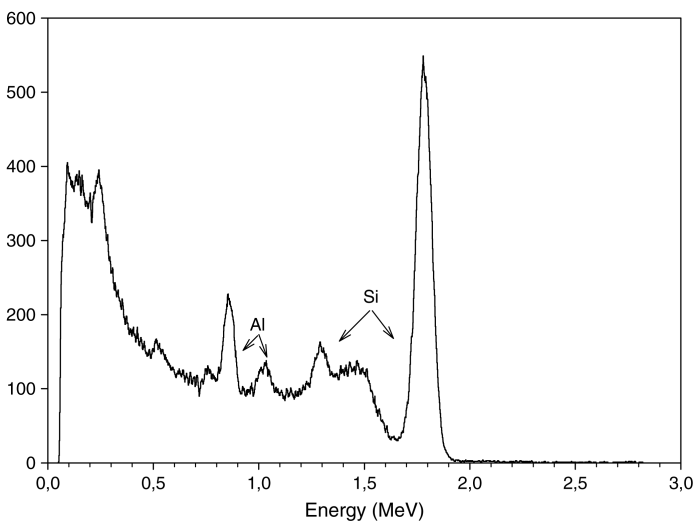

Fig. 4. Gamma-ray spectrum of a dry soil sample irradiated by the neutron beam. Aluminum was detected by the $0.84 \mathrm{MeV}$ and $1.01 \mathrm{MeV}$ lines of ${ }^{27} \mathrm{Mg}$ (half life $9.46 \mathrm{~min}$ ) coming from the ${ }^{27} \mathrm{Al}(\mathrm{n} . \mathrm{p}){ }^{27} \mathrm{Mg}$ nuclear reaction. Similarly, silicon was detected by the $1.78 \mathrm{MeV}$ and $1.28 \mathrm{MeV}$ lines of ${ }^{28} \mathrm{Al}$ (half life $2.24 \mathrm{~min}$ ) and ${ }^{29} \mathrm{Al}$ (half life $6.56 \mathrm{~min}$ ) coming from the ${ }^{28} \mathrm{Si}(\mathrm{n}, \mathrm{p})^{28} \mathrm{Al}$ and ${ }^{29} \mathrm{Si}(\mathrm{n}, \mathrm{p}){ }^{29} \mathrm{Al}$ nuclear reactions, respectively. FN activation analysis was used with $7.62 \mathrm{~cm} \times 7.62 \mathrm{~cm} \mathrm{NaI}(\mathrm{Tl})$ gamma-ray detector.
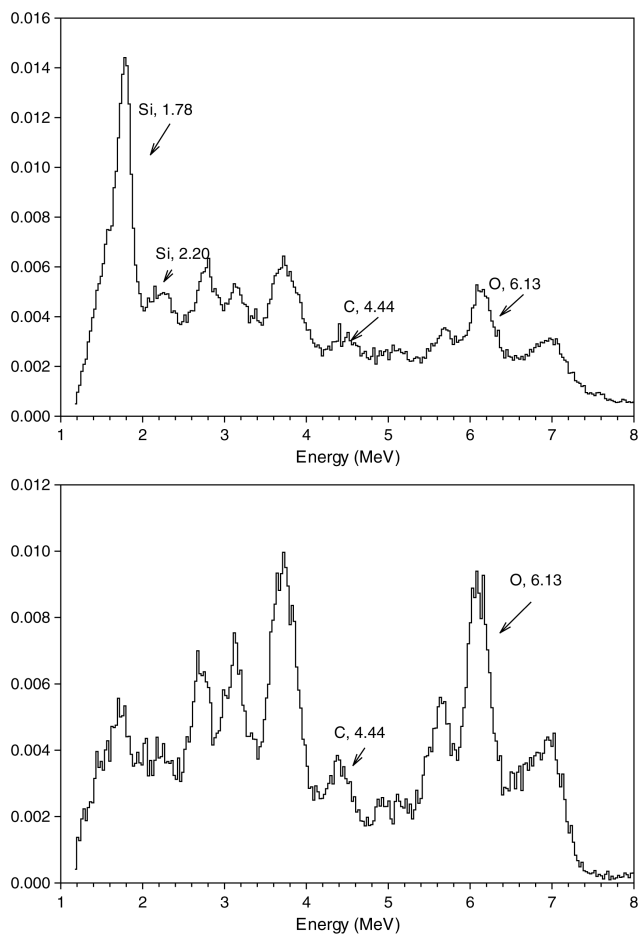

Fig. 5. Gamma-ray spectrum of silicon dioxide (upper) and the gamma ray spectrum of water (lower) in a plastic container. Recorded with the BGO gamma-ray detector.

surrogate gamma ray spectrum. Carbon, oxygen, silicon and aluminum peaks were visible in the gamma-ray spectrum of dry soil. Presence of aluminum and silicon in the soil was confirmed by the FN activation analysis (activation spectrum recorded after irradiation was stopped, see Fig. 4). Fig. 5 shows the normalized gamma-ray spectra of $\mathrm{SiO}_{2}$ and water.

Both samples were in one-liter plastic container. It should be noted that the silicon has a peak at approximately $2.2 \mathrm{MeV}$ with unknown origin (it was not reported in [11]). A small silicon peak of this energy was also seen in [12]. Regardless of the origin of the peak, its presence detected in soils containing 


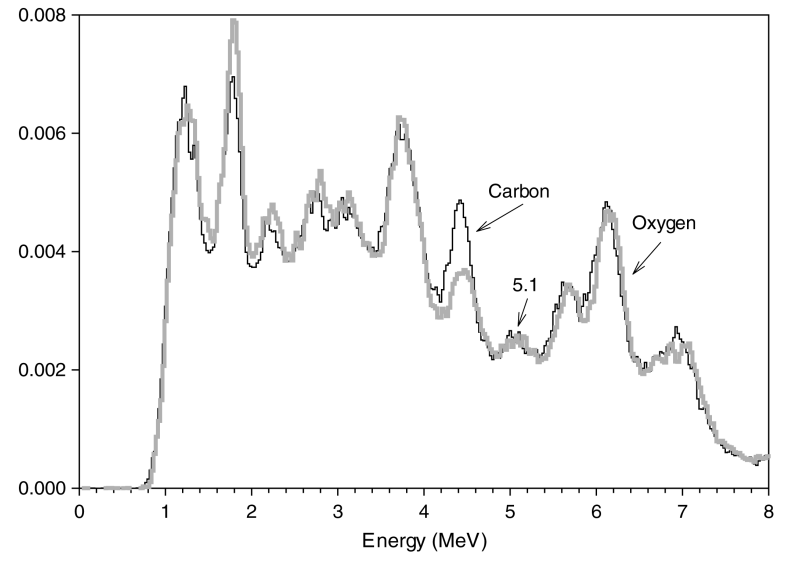

Fig. 6. Gamma-ray spectrum of the DLM2.4 in soil (black) and the gamma ray spectrum of soil alone (gray). Recorded with the BGO gamma-ray detector.

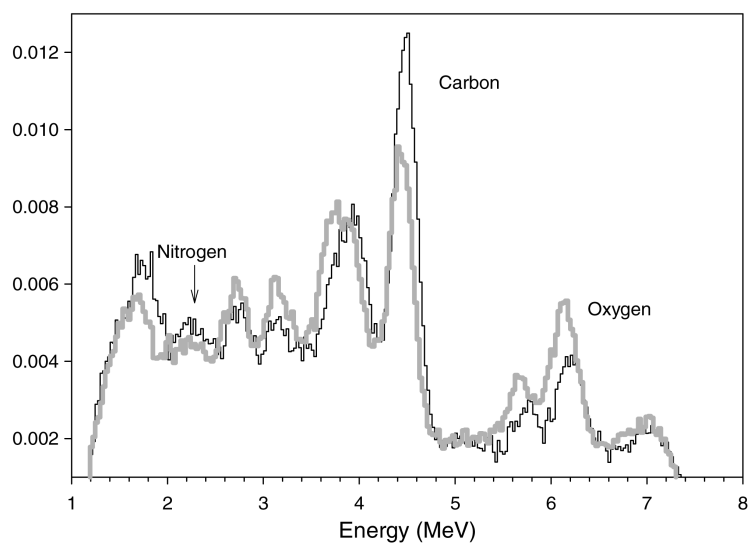

Fig. 7. Gamma-ray spectrum of DLM2.4 (black) and the gamma ray spectrum of paper (gray). Recorded with the BGO gamma-ray detector.

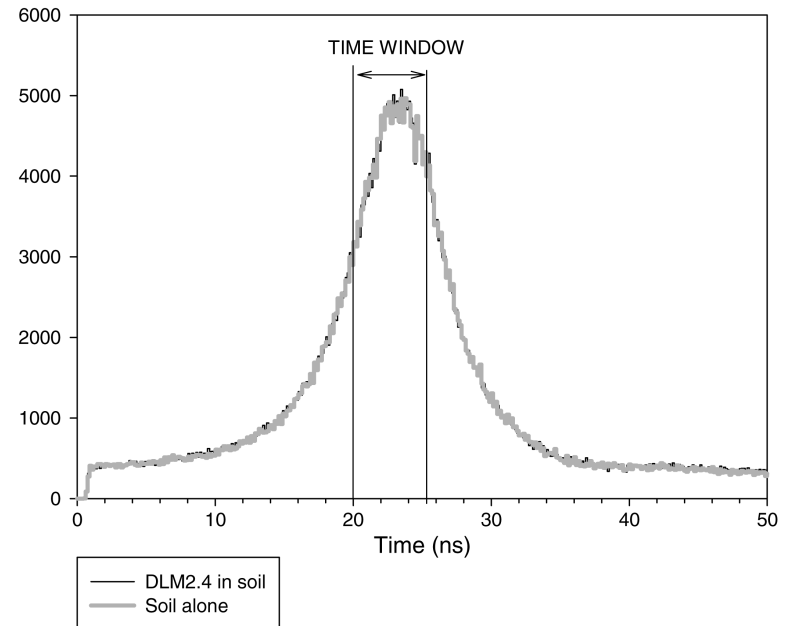

Fig. 8. Time-of-flight spectrum of the DLM2.4 in soil (black) and the time-offlight spectrum of soil alone (gray). The soil moisture content was $0.96 \% \mathrm{wt}$. The gamma-ray detector was $7.62 \mathrm{~cm} \times 7.62 \mathrm{~cm} \mathrm{BGO}$.

aluminum and silicon ruins the possibility of nitrogen detection

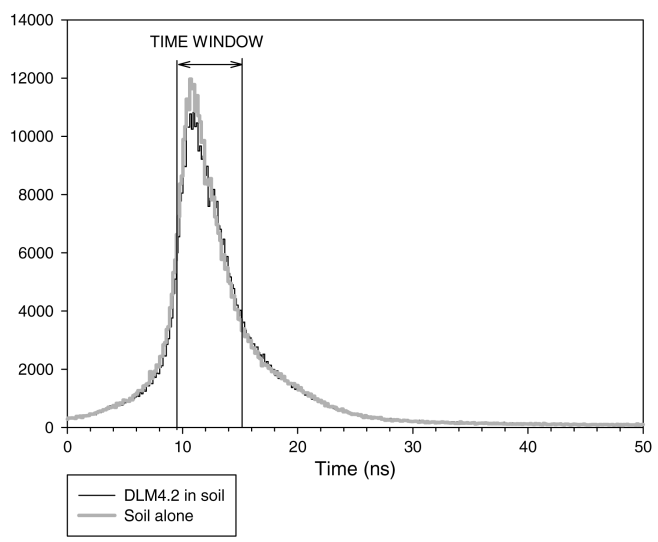

Fig. 9. Time-of-flight spectrum of the DLM2.4 in soil (black) and the time-offlight spectrum of soil alone (gray). The soil moisture content was $0.96 \%$ wt. The gamma-ray detector was $7.62 \mathrm{~cm} \times 7.62 \mathrm{~cm} \mathrm{LaBr}_{3}: \mathrm{Ce}$.

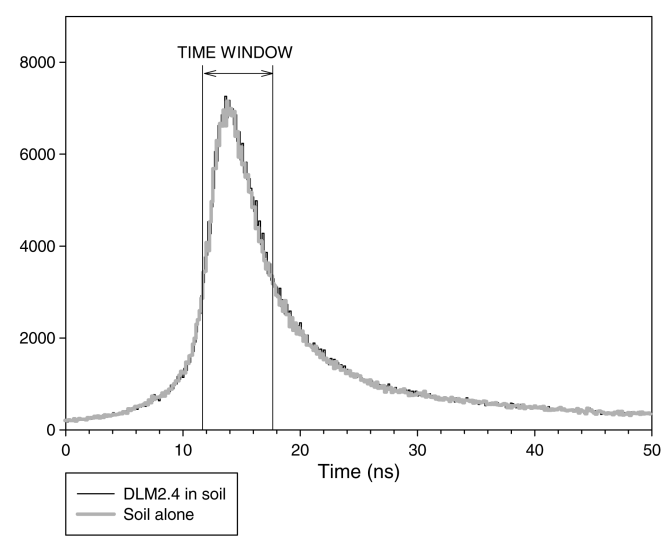

Fig. 10. Time-of-flight spectrum of the DLM2.4 in soil (black) and the time-offlight spectrum of soil alone (gray). The soil moisture content was $0.96 \%$ wt. The gamma-ray detector was $7.62 \mathrm{~cm} \times 7.62 \mathrm{~cm} \mathrm{NaI}(\mathrm{Tl})$.

at least in small AP mines field with the TNT explosive only. Fig. 6 shows the gamma-ray spectrum of DLM2.4 buried in soil (black) and the gamma-ray spectrum of soil alone (gray). DLM2.4 is a simulant of an AP mine [13]. It has chemical composition and the density the same as the TNT explosive. Its mass was $192.6 \mathrm{~g}$ and volume $\Phi 80 \mathrm{~mm} \times 34.5 \mathrm{~mm}$.

Nitrogen was not detected in the buried DLM2.4 mine. The only clear difference between the mine in soil and the soil alone was in the carbon content.

Fig. 7 shows the gamma-ray spectrum of DLM2.4 (black) and the gamma ray spectrum of paper (gray). Without the presence of soil, the nitrogen line at $2.31 \mathrm{MeV}$ was detected, although weakly after a long measurement time. The gamma-ray spectrum of paper differs from the DLM2.4 gamma-ray spectrum in a $\mathrm{C} / \mathrm{O}$ ratio. Paper, which is rich in carbon, was analyzed with the purpose to simulate wood since some difficulties in TNT detection based on carbon content measurement could be expected in vicinities of trees.

Similar results were obtained by using the $7.62 \mathrm{~cm} \times$ $7.62 \mathrm{~cm} \mathrm{LaBr} 3$ : Ce gamma-ray detector. 

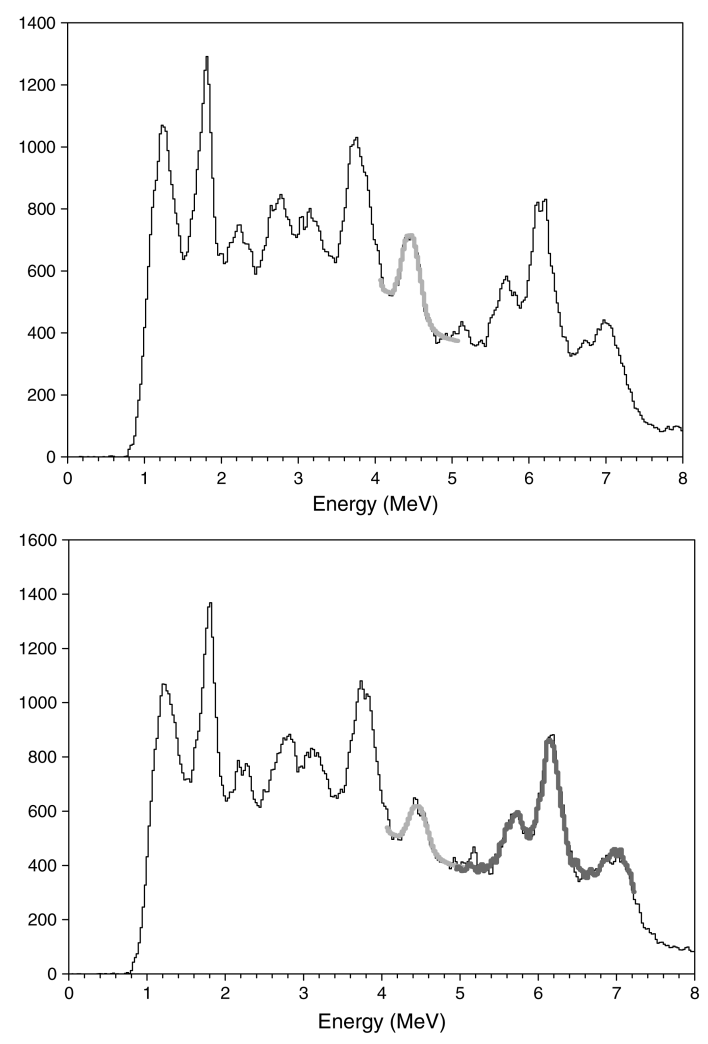

Fig. 11. Gamma-ray spectrum of DLM2.4 in the soil (upper) and the gamma-ray spectrum of soil alone (lower). Fitting curves are in gray (fitting part one) and dark gray color (fitting part two). The soil moisture content was $6.3 \%$ wt. The gamma-ray detector was $7.62 \mathrm{~cm} \times 7.62 \mathrm{~cm} \mathrm{BGO}$.

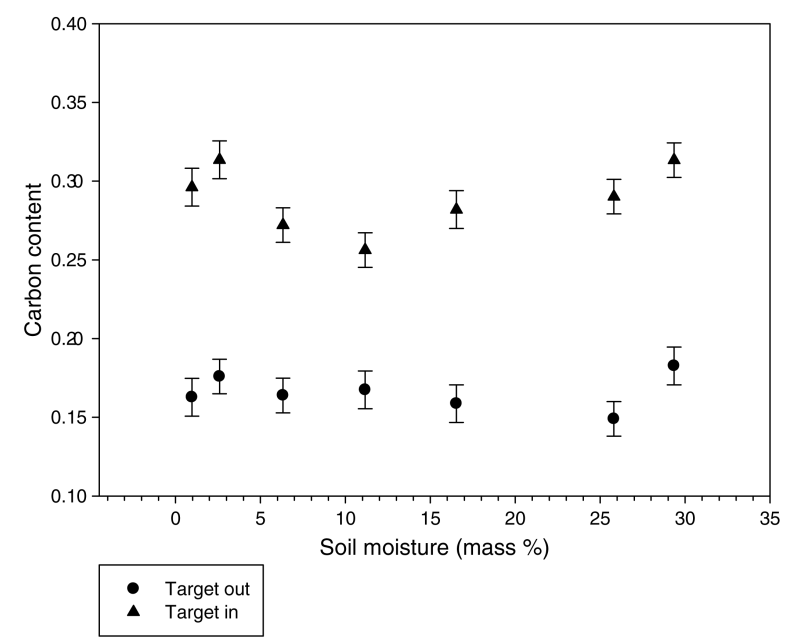

Fig. 12. Carbon content in dependence on the soil moisture. BGO was used as gamma-ray detector.

\section{SoIL Moisture AND its Relevance to the TNT EXPLOSIVE DETECTION}

Comparative studies were done for $\mathrm{BGO}, \mathrm{LaBr}_{3}$ : Ce and $\mathrm{NaI}(\mathrm{Tl})$ gamma ray detectors. Simulant of the AP mine DLM2.4 was buried in wet loam soil of $29.3 \mathrm{~kg}$, closed to the soil surface, covered with about $2 \mathrm{~cm}$ of soil. Distance between the soil surface and the gamma-ray detectors was around $2.5 \mathrm{~cm}$. Measurements were done for the target in, target out configuration
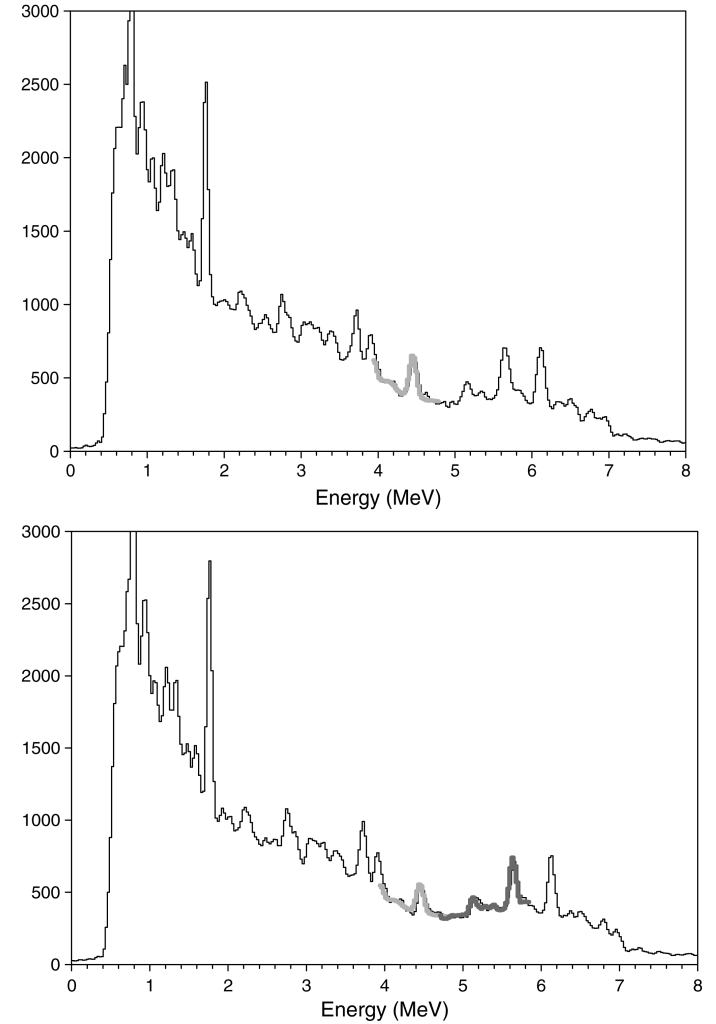

Fig. 13. Gamma-ray spectrum of DLM2.4 in the soil (upper) and the gamma ray spectrum of soil alone (lower). Fitting curves are in gray (fitting part one) and dark gray color (fitting part two). The soil moisture content was $6.3 \%$ wt. $\mathrm{LaBr}_{3}$ : Ce was used as the gamma-ray detector.

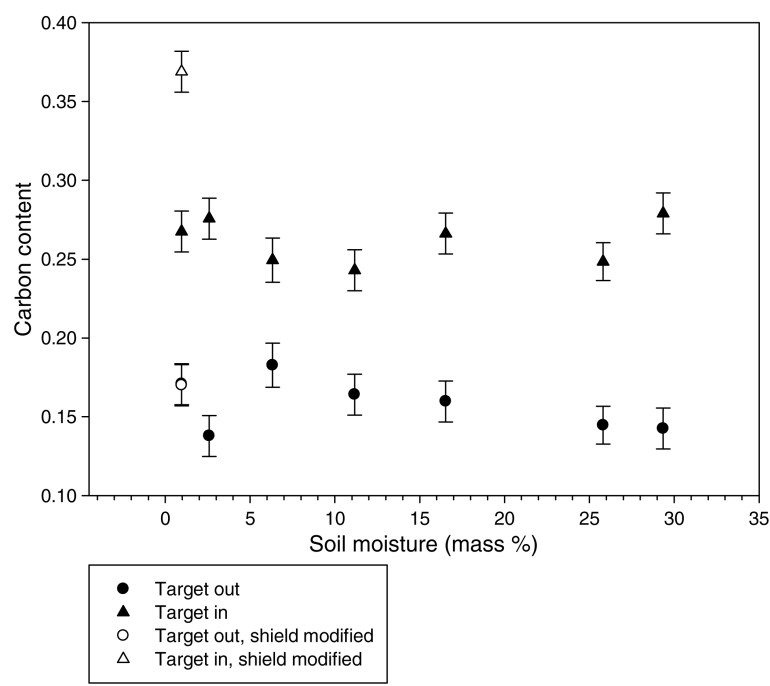

Fig. 14. Carbon content in dependence on the soil moisture. The $\mathrm{LaBr}_{3}: \mathrm{Ce}$ was used as gamma-ray detector.

every few days. During that time soil was drying naturally. Neutron beam intensity was approximately $2 \times 10^{7} \mathrm{n} / \mathrm{s}$.

Figs. 8, 9 and 10 show examples of time-of-flight spectra for target in (black) and target out (gray) configurations for the $\mathrm{BGO}, \mathrm{LaBr}_{3}$ : Ce and $\mathrm{NaI}(\mathrm{Tl})$ gamma ray detectors respectively. The selected time windows were indicated. For the target close to the surface it is better to choose a wider time window. 

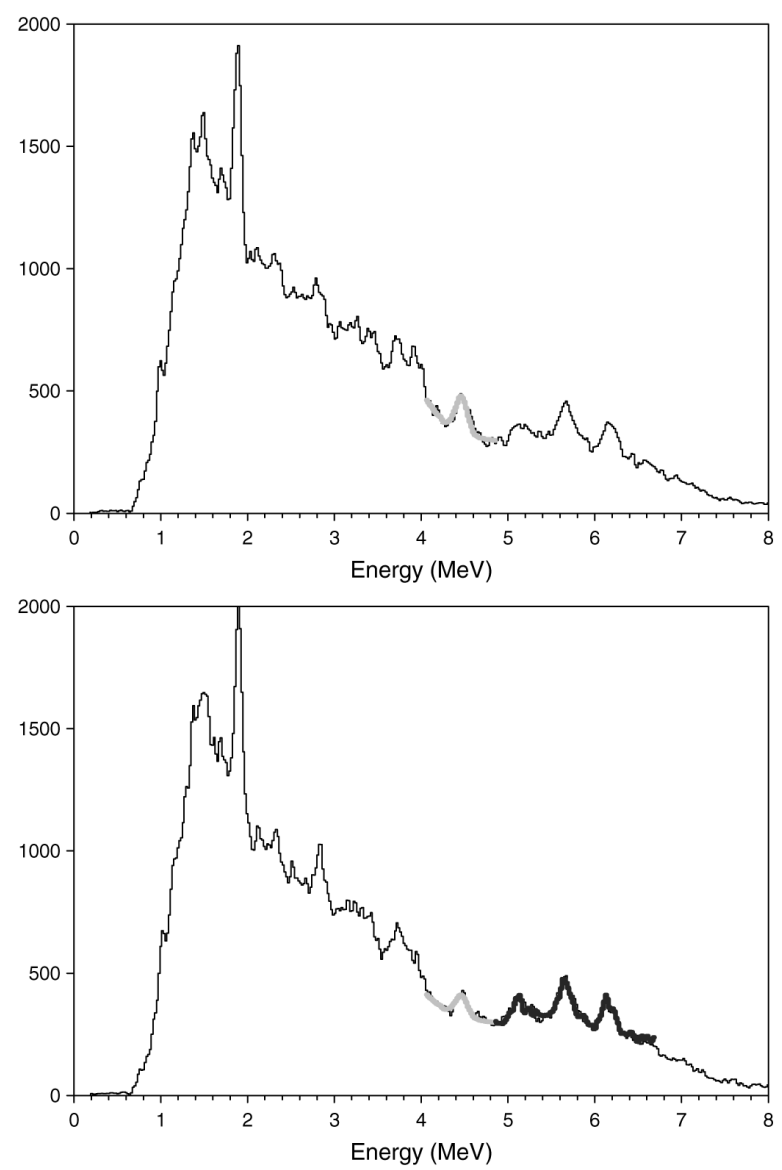

Fig. 15. Gamma-ray spectrum of DLM2.4 in the soil (upper) and the gamma-ray spectrum of soil alone (lower). Fitting curves are in gray (fitting part one) and dark gray color (fitting part two). The soil moisture content was $6.3 \%$ wt. The gamma-ray detector was $7.62 \mathrm{~cm} \times 7.62 \mathrm{~cm} \mathrm{NaI}(\mathrm{Tl})$.

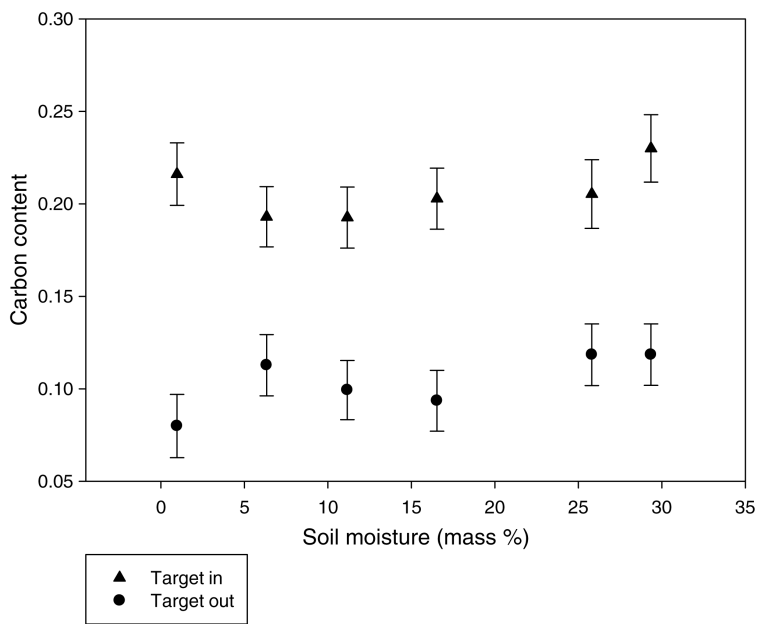

Fig. 16. Carbon content in dependence on the soil moisture. $\mathrm{NaI}(\mathrm{Tl})$ was used as gamma-ray detector.

In the wider time window the gamma-ray spectra have more statistics (counts) and accordingly, smaller error bars in the gamma-ray peaks, which improves the detection probability. For the target deeper in the soil the time window must be smaller, see [1]. There is no difference in the time-of-flight spectra between the target in and target out configurations. By

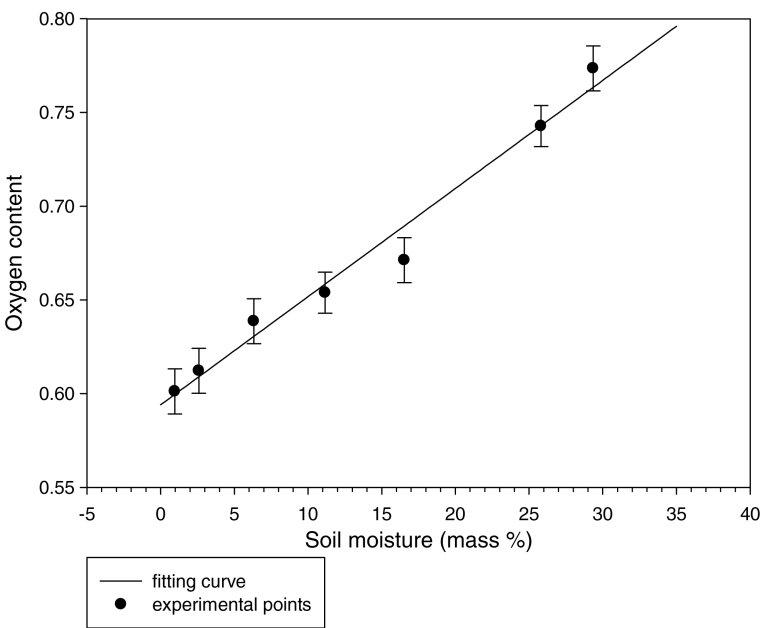

Fig. 17. Oxygen content in dependence on the soil moisture with BGO used as gamma-ray detector.

selecting the indicated time window and after the random background subtraction the gamma-ray spectra were obtained like in Figs. 11, 13 and 15. Two different parts of the spectra were fitted separately, one in the range 4-5 MeV and another one in the range 5-7.2 MeV for the setup with BGO detector. For the setup with $\mathrm{LaBr}_{3}$ : Ce detector the second part was shorter, 4.7-5.8 MeV and for $\mathrm{NaI}(\mathrm{Tl})$ 4.8-6.7 MeV, because fitting was found to be more difficult in the $\mathrm{LaBr}_{3}$ : Ce case than in the BGO case. Namely, each time the gamma-ray detector was changed, the high voltage was switched on and off. Although the high voltage was put on the same value each time after the replacement, the shifting in the energy calibration was noticed in the $\mathrm{LaBr} 3: \mathrm{Ce}$ case up to $10 \%$, in the $\mathrm{NaI}(\mathrm{Tl})$ up to $2 \%$ and in the BGO case up to $1 \%$.

The fitting procedure was done by using (1) where the sum was done over the channel (ch) number. Carbon is pure elemental spectrum. Parameters "a", "b" and "c" are fitting parameters. Parameter "a" measure the carbon content, while parameters "b" and "c" measures the background below the $4.44 \mathrm{MeV}$ carbon peak. Similarly, the fitting procedure was done in the oxygen region from which the oxygen content was extracted. The method of least squares states that the best values of "a", "b" and "c" are those for which chi-square is a minimum.

Fig. 12 shows carbon content obtained by BGO detector for target in and target out configurations in dependence of moisture content. Carbon content was constant and did not depend on the soil moisture.

$$
\begin{aligned}
& \chi^{2}=\frac{s u m m^{2}}{c h_{\max }-c h_{\min }-2} \\
& \times \sum_{c h=c h_{\min }}^{c h=c h_{\max }} \frac{\left(\operatorname{axcarbon}(c h)+\frac{b}{c h}+c-\frac{\text { Target }(c h)}{\text { summ }}\right)^{2}}{\text { Target }(\text { ch })} \\
& \sum_{c h=c h_{\text {min }}}^{c h=c h_{\text {max }}} \text { Target }(\text { ch })=\text { summ } \\
& \sum_{c h=c h_{\min }}^{c h=c h_{\max }} \operatorname{carbon}(c h)=1
\end{aligned}
$$

However, it does depend on geometry, soil surface shape and on exact position of the mine corresponding to the position of 


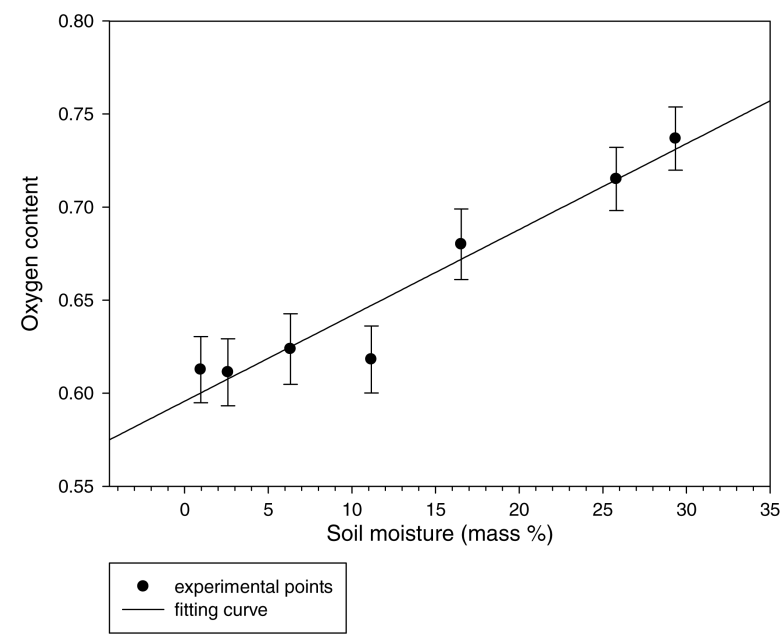

Fig. 18. Oxygen content in dependence on the soil moisture. $\mathrm{LaBr}_{3}:$ Ce was used as the gamma-ray detector.

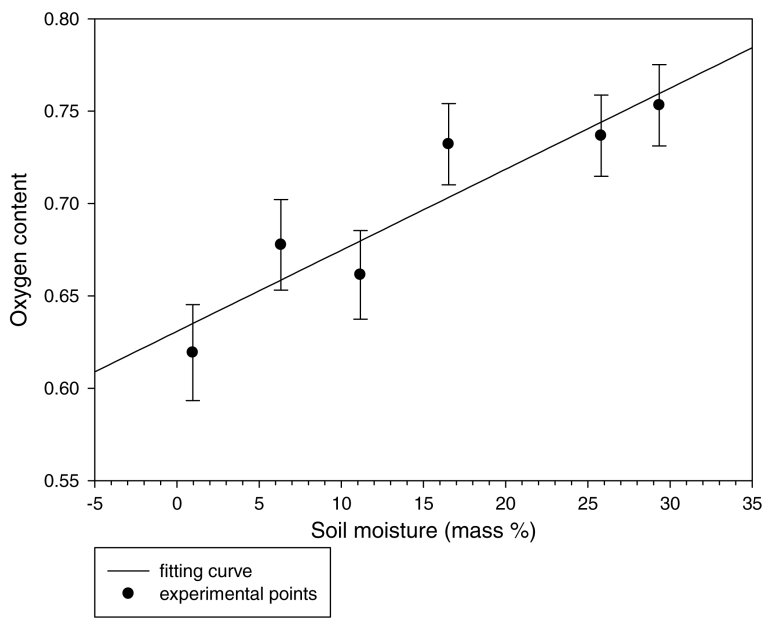

Fig. 19. Oxygen content in dependence on the soil moisture. $\mathrm{NaI}(\mathrm{Tl})$ was used as the gamma-ray detector.

the tagged neutron cone. Fig. 14 shows the carbon content in dependence on the soil moisture with $\mathrm{LaBr}_{3}$ : Ce used. Difference in carbon content between target in and target out configurations is somewhat smaller than for BGO. It was found latter that better results were obtained when position of the protecting shield was modified (measurements in white color). The shield modification improves the measurements with the BGO and $\mathrm{NaI}(\mathrm{Tl})$ detectors also. Fig. 16 shows the carbon content in dependence on the soil moisture with $\mathrm{NaI}(\mathrm{Tl})$ used (shield position not modified). While the difference in carbon content between target in and target out configurations is similar to the $\mathrm{LaBr}_{3}$ : Ce case, error bars are larger. Contrary to the carbon content, the oxygen content depended on the soil moisture as it was expected. Figs. 17, 18 and 19 show the fitted oxygen content in dependence of soil moisture for the $\mathrm{BGO}, \mathrm{LaBr}_{3}: \mathrm{Ce}$ and $\mathrm{NaI}(\mathrm{Tl})$ detectors, respectively.

The soil moisture content may also be measured by measuring the hydrogen content. The hydrogen can be measured by detecting its capture gamma ray line at $2.2 \mathrm{MeV}$, which is usually part of a random background spectrum.

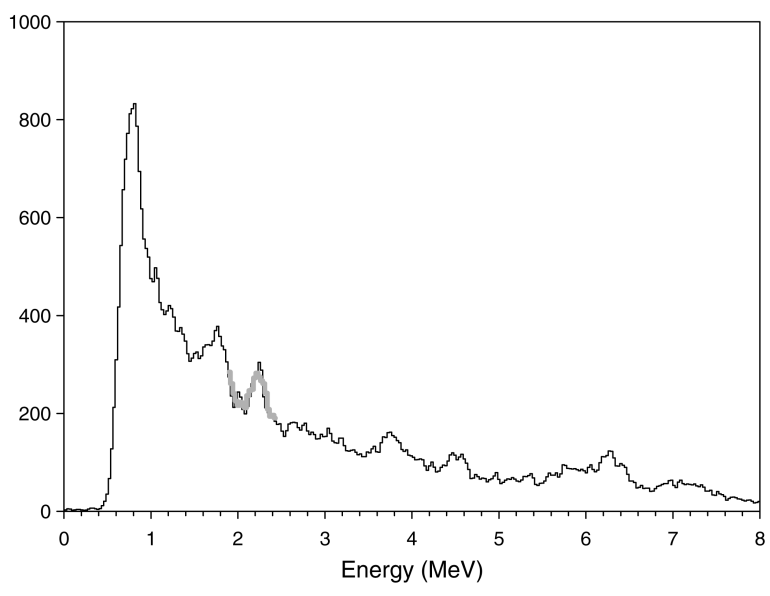

Fig. 20. Random background energy spectrum. Fitting curve is in a gray color. BGO was used as gamma-ray detector.

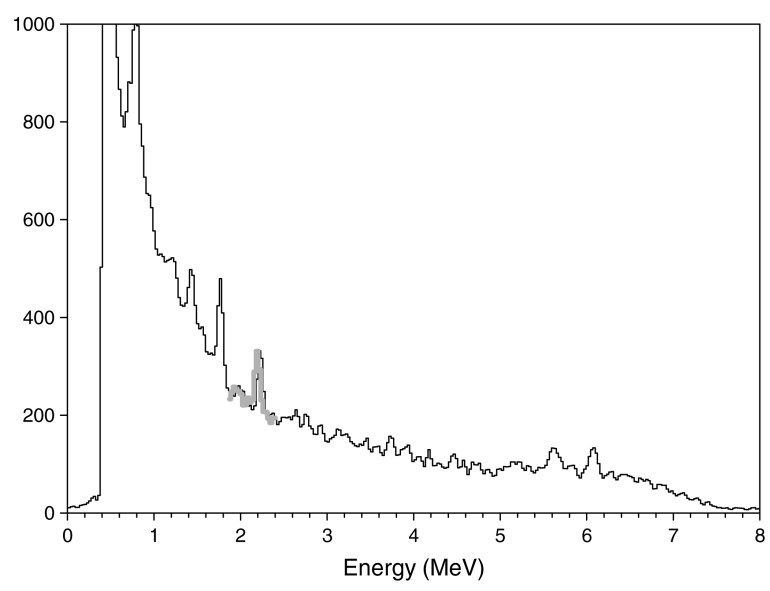

Fig. 21. Random background energy spectrum. Fitting curve is in a gray color. $\mathrm{LaBr}_{3}$ : Ce was used as gamma-ray detector.

Figs. 20, 21 and 22 show the random background energy spectrum for the $\mathrm{BGO}, \mathrm{LaBr}_{3}$ : $\mathrm{Ce}$ and $\mathrm{NaI}(\mathrm{Tl})$ detectors, respectively. Fitting curves (found by using eq. 1 with Carbon (ch) replaced by Hydrogen (ch)) at $2.2 \mathrm{MeV}$ are in gray color. Figs. 23, 24 and 25 show the hydrogen content in dependence on soil moisture content for $\mathrm{BGO}, \mathrm{LaBr}_{3}$ : $\mathrm{Ce}$ and $\mathrm{NaI}(\mathrm{Tl})$ gamma-ray detectors, respectively.

\section{Detection Probability of Finding the DLM2.4 Mine IN SOIL}

The difference in carbon content between soil and TNT explosive enables detection of the AP mine. Fig. 26 shows theoretical normal distributions of the carbon content in soil (top curve) and from the mine buried into the soil (bottom curve). It can be seen that two distributions overlap partially. Overlapping decreases as the time of measurement extends. False positive is defined by an area over the threshold of the carbon distribution in the soil. Detection probability is defined by an area over the threshold of the carbon distribution from mine buried into the soil. Threshold is defined by the formula:

Threshold $=$ Average background $+\kappa \sigma_{b}($ see Fig. 26), 


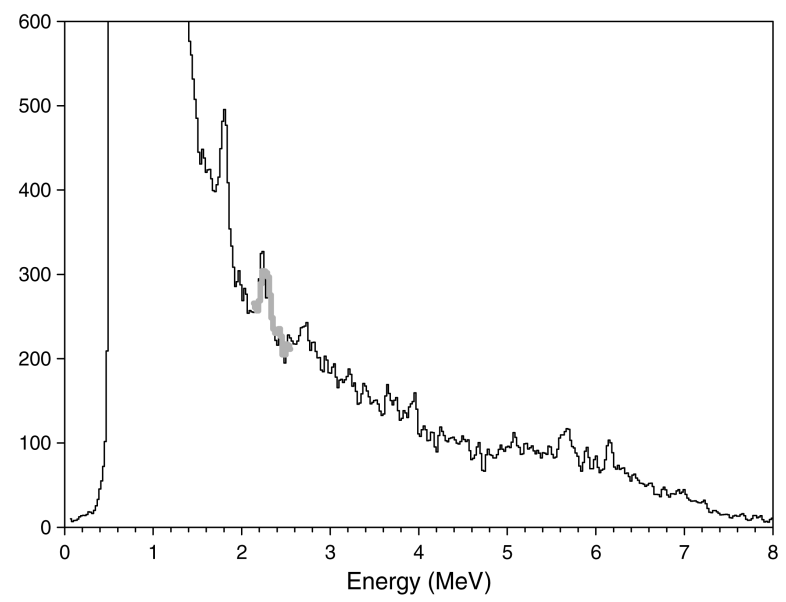

Fig. 22. Random background energy spectrum. Fitting curve is in a gray color. $\mathrm{NaI}(\mathrm{Tl})$ was used as gamma-ray detector.

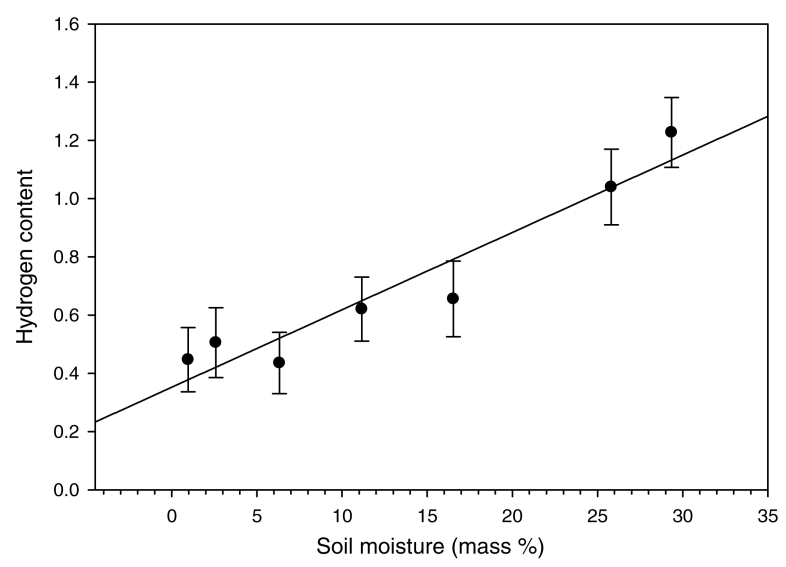

- experimental points fitting curve

Fig. 23. Hydrogen content in dependence on the soil moisture. The gamma-ray detector was $7.62 \mathrm{~cm} \times 7.62 \mathrm{~cm}$ BGO.

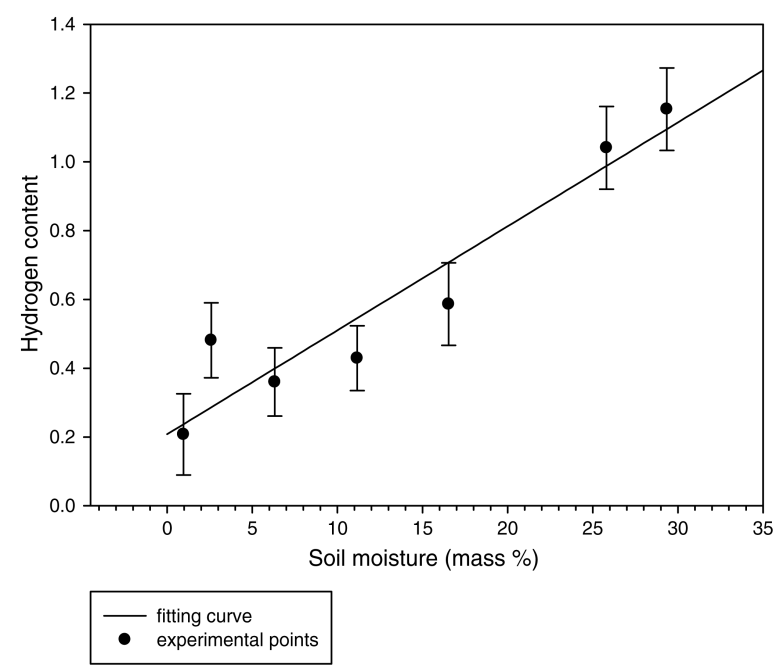

Fig. 24. Hydrogen content in dependence on the soil moisture. The gamma-ray detector was $7.62 \mathrm{~cm} \times 7.62 \mathrm{~cm} \mathrm{LaBr}_{3}: \mathrm{Ce}$.

where parameter $\kappa$ depends on the accepted false positive alarm rate. In this research $\kappa=1.282$, coresponding to the $10 \%$ level

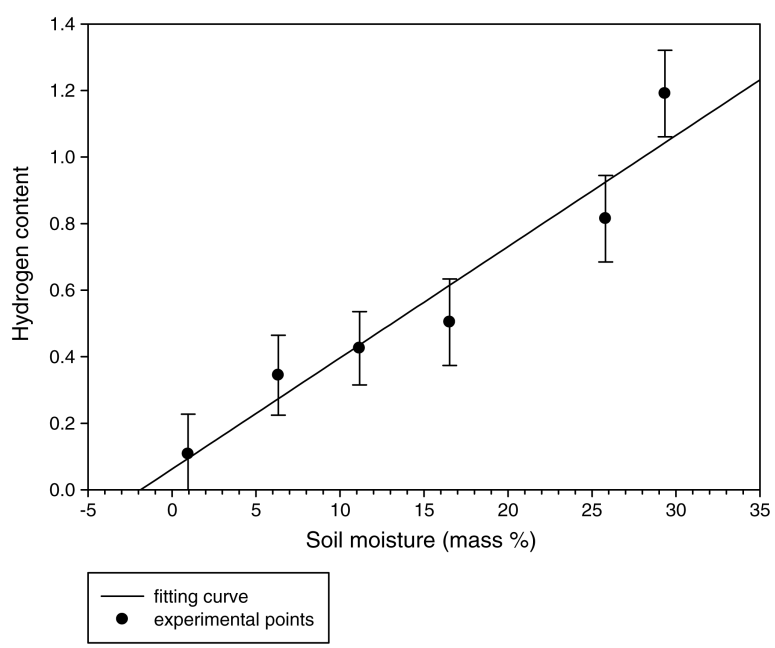

Fig. 25. Hydrogen content in dependence on the soil moisture. The gamma-ray detector was $7.62 \mathrm{~cm} \times 7.62 \mathrm{~cm} \mathrm{NaI}(\mathrm{Tl})$.

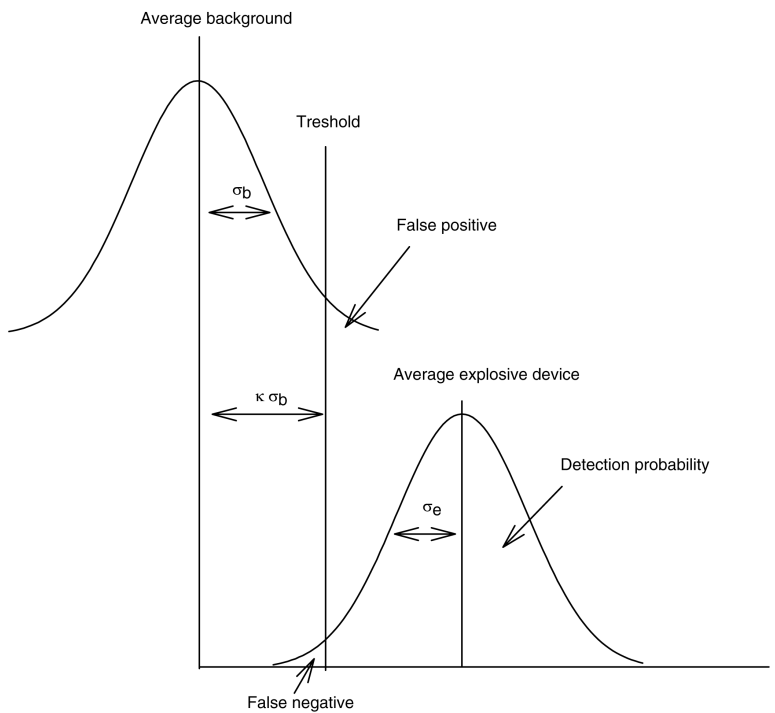

Fig. 26. Normal distribution for the carbon content in the soil and for the carbon content in TNT fragment/explosive device buried into the soil.

TABLE I

Detection Probability and CARbon CONTENT For TARget IN/TARget Out CONFigurations. The GAMma-RAy Detector IS $7.62 \mathrm{~cm} \times 7.62 \mathrm{~cm}$ BGO

\begin{tabular}{|c|c|c|c|}
\hline \hline Time (s) & Target in & Target out & $\begin{array}{c}\text { Detection prob. } \\
(\%)\end{array}$ \\
\hline 1255 & $0.289 \pm 0.011$ & $0.166 \pm 0.011$ & 100 \\
\hline 209 & $0.290 \pm 0.028$ & $0.166 \pm 0.028$ & 99.9 \\
\hline 157 & $0.290 \pm 0.033$ & $0.166 \pm 0.033$ & 99.4 \\
\hline 106 & $0.289 \pm 0.04$ & $0.167 \pm 0.04$ & 96.3 \\
\hline 70 & $0.289 \pm 0.049$ & $0.166 \pm 0.049$ & 89.1 \\
\hline 52 & $0.289 \pm 0.056$ & $0.166 \pm 0.056$ & 81.9 \\
\hline
\end{tabular}

of false positive. Table I shows the detection probability and carbon content for target in, target out configurations in the case of BGO gamma-ray detector. Table II and III show results for 
TABLE II

Detection Probability AND CARbon CONTENT For TARget In/TARgET Out CONFIGURATIONS. $\mathrm{LaBr}_{3}$ : Ce WAS Used AS THE GAMMA-RAY DETECTOR

\begin{tabular}{|c|c|c|c|}
\hline \hline Time (s) & Target in & Target out & $\begin{array}{c}\text { Detection prob. } \\
(\%)\end{array}$ \\
\hline 1255 & $0.260 \pm 0.013$ & $0.156 \pm 0.013$ & 100 \\
\hline 209 & $0.261 \pm 0.032$ & $0.154 \pm 0.032$ & 98 \\
\hline 157 & $0.261 \pm 0.037$ & $0.155 \pm 0.037$ & 94.6 \\
\hline 106 & $0.261 \pm 0.045$ & $0.154 \pm 0.045$ & 86.6 \\
\hline 70 & $0.262 \pm 0.055$ & $0.157 \pm 0.055$ & 73.4 \\
\hline 52 & $0.265 \pm 0.063$ & $0.155 \pm 0.063$ & 67.6 \\
\hline
\end{tabular}

TABLE III

Detection Probability ANd CARBon CONTENT FOR TARgET IN/TARget Out CONFigurations. NaI(TL) WAS USED AS THE GAMma-RaY Detector

\begin{tabular}{|c|c|c|c|}
\hline \hline Time (s) & Target in & Target out & $\begin{array}{c}\text { Detection prob. } \\
(\%)\end{array}$ \\
\hline 1255 & $0.207 \pm 0.017$ & $0.104 \pm 0.017$ & 100 \\
\hline 209 & $0.206 \pm 0.042$ & $0.105 \pm 0.040$ & 88 \\
\hline 157 & $0.207 \pm 0.048$ & $0.104 \pm 0.047$ & 81 \\
\hline 106 & $0.207 \pm 0.059$ & $0.104 \pm 0.057$ & 69 \\
\hline 70 & $0.208 \pm 0.072$ & $0.106 \pm 0.070$ & 57 \\
\hline 52 & $0.211 \pm 0.083$ & $0.107 \pm 0.080$ & 51 \\
\hline
\end{tabular}

$\mathrm{LaBr}_{3}: \mathrm{Ce}$ and $\mathrm{NaI}(\mathrm{Tl})$ detectors. Data were averaged over the soil moisture content. The uncertainties arise from the fitting procedure. While the average carbon content was more or less the same, or otherwise did not depend on the measurement time, the uncertainties increase as measurement time decreases.

Evidently, the BGO detector shows better results in comparison to the $\mathrm{LaBr}_{3}$ : Ce and $\mathrm{NaI}(\mathrm{Tl})$ detectors. It can detect the AP mine in shorter time.

Systematic error was found in the position of the iron shield between the gamma-ray detector and the NG. After shielding was modified in order to open detector more with respect to gamma rays (it was over shielded), better results were obtained with $\mathrm{LaBr}_{3}$ : Ce, which are presented in Table IV.

It should be noted that the neutron beam intensity was three times less than in reference [1]. Because of the limitations of the NG used in this research, we could not achieve a higher neutron flux. If we take into account the differences in intensities used, the results from Table III are consistent with those obtained in [1] with $6 \cdot 10^{7} \mathrm{n} / \mathrm{s}$ emission.

\section{SUMMARY}

Although nitrogen can be used for the TNT explosive detection, it was found that the best way to detect its small quantities is by measuring the carbon content. The method can be used regardless of the soil moisture content. Some problems could be expected during detection in the vicinity of trees. Since the method presented was developed to work in compliance with
TABLE IV

Detection Probability and CARbon CONTENT For TARget IN/TARget OUT CONFIGURATIONS. $\mathrm{LaBr}_{3}$ : Ce WAS USED AS THE GAMMA-RAY Detector After Iron SHIEld was Modified. SoIl Moisture WAS $1 \%$ WT

\begin{tabular}{|c|c|c|c|}
\hline \hline Time (s) & Target in & Target out & $\begin{array}{c}\text { Detection prob. } \\
(\%)\end{array}$ \\
\hline 1255 & $0.369 \pm 0.013$ & $0.170 \pm 0.013$ & 100 \\
\hline 209 & $0.369 \pm 0.032$ & $0.168 \pm 0.031$ & 100 \\
\hline 157 & $0.371 \pm 0.036$ & $0.171 \pm 0.036$ & 100 \\
\hline 106 & $0.370 \pm 0.045$ & $0.171 \pm 0.044$ & 99.9 \\
\hline 90 & $0.370 \pm 0.048$ & $0.172 \pm 0.047$ & 99.8 \\
\hline 78 & $0.370 \pm 0.051$ & $0.178 \pm 0.051$ & 99.3 \\
\hline 70 & $0.371 \pm 0.055$ & $0.174 \pm 0.054$ & 99 \\
\hline 52 & $0.375 \pm 0.063$ & $0.173 \pm 0.062$ & 97.4 \\
\hline
\end{tabular}

other sensors by using MV-4/MV-10 vehicles which are not designed for work in woods, we were not focused to this particular problem. Among the three types of gamma-ray detectors studied in this paper, the $7.62 \mathrm{~cm} \times 7.62 \mathrm{~cm} \mathrm{BGO}$ was found to be the best choice. It is more stable with respect to the energy calibration shifting, and it is less expensive compared to $\mathrm{LaBr}_{3}: \mathrm{Ce}$ of the same dimensions, while the $7.62 \mathrm{~cm} \times 7.62 \mathrm{~cm} \mathrm{NaI}(\mathrm{Tl})$ has poor efficiency compared to the BGO. By using BGO and the NG which can provide neutron beam intensities of more than $2 \times 10^{7} \mathrm{n} / \mathrm{s}$, the AP mine/TNT explosive residue can be found in less than a minute. However, the desired demining vehicle speed of $10 \mathrm{~cm} / \mathrm{s}$ can hardly be obtained by using FN-API method only. By combination of the several methods like GPR, MD, IR and FN-API, the desired speed could be obtained.

\section{REFERENCES}

[1] D. Sudac et al., "Inspecting minefield and residual explosives by fast neutron activation method," IEEE Trans. Nucl. Sci., vol. 59, pt. 4 Part 2, pp. 1421-1425, 2012, 6036201.

[2] A. A. Faust et al., "Canadian teleoperated landmine detection systems. Part I: The improved landmine detection project," Int. J. Systems Sci., vol. 36, no. 9, pp. 529-543, 2005.

[3] A. A. Faust et al., "Canadian teleoperated landmine detection systems. Part II: Antipersonnel landmine detection," Int. J. Systems Sci., vol. 36, no. 9, pp. 529-543, 2005.

[4] C. Bruchini et al., "Ground penetrating radar and imaging metal detector for antipersonnel mine detection," J. Appl. Geophys., vol. 40, pp. 59-71, 1998.

[5] O. Lopera and N. Milisavljevic, "Prediction of the effects of soil and target properties on the antipersonnel landmine detection performance of ground-penetrating radar: A Columbian case study," J. Appl. Geophys., vol. 63, pp. 13-23, 2007.

[6] T. W. Miller, J. M. H. Hendrickx, and B. Brochers, "Radar detection of buried landmines in field soils," Vadose Zone Journale, vol. 3, no. 4, pp. 1116-1127, 2004.

[7] B. S. Das, J. M. H. Hendrickx, and B. Brochers, "Modeling transient water distributions around landmines in bare soils," Soil Sci., vol. 166, no. 3, pp. 163-173, 2001.

[8] T. Kazunori, H. Preetz, and J. Igel, "Soil properties and performance of landmine detection by metal detector and ground-penetrating radarSoil characterization and its verification by field test," J. Appl. Geophys., vol. 73, pp. 368-377, 2011.

[9] V. M. Bystritsky et al., "Study of the associated particle imaging technique for the hidden explosives identification," in Proc. Int. Conf. Requirements Technol. for the Detection, Removal and Neutralization of Landmines and UXO, EUDEM2-SCOT-2003, , Brussels, Belgium, Sep. 15-18, 2003, vol. 1,2 [Online]. Available: http://ntech.jinr.ru/?id=publications, Vrije Universiteit Brussel, 
[10] V. M. Bystritsky et al., "Study of nuclear physics methods of identification of hidden substances in JINR," in Proc. Int. Scientific Techn. Conf. , Moscow, Oct. 18-22, 2004, p. 283 [Online]. Available: http:// ntech.jinr.ru/?id=publications

[11] S. P. Simakov, A. Pavlik, H. Vonach, and S. Hlavac, "Status of experimental and evaluated discrete gamma-ray production at $\mathrm{En}=$ 14.5 MeV," IAEA Nuclear Data Section, INDC(CCP)-413, 1998 [Online]. Available: http://www-nds.iaea.org/reports-new/indc-reports/indc-ccp/
[12] W. El Kanawati et al., "Acquisition of prompt gamma-ray spectra induced by $14 \mathrm{MeV}$ neutrons and comparison with Monte Carlo simulations," Appl. Radiation Isotopes, vol. 69, pp. 732-743, 2011.

[13] F. D. Brooks et al., "Detection of anti-personnel landmines by neutron scattering and attenuation," Appl. Radiation Isotopes, vol. 61, pp. 27-34, 2004. 